УДК 378.4:303.722.4

МЕЖДИСЦИПЛИНАРНЫЕ ИССЛЕДОВАНИЯ

ББК 65

\title{
ФОРМИРОВАНИЕ ОБРАЗОВАТЕЛЬНОЙ СРЕДЫ (КЛАСТЕРА)
}

\author{
А.Ю. ЧИГАРИН
}

сотрудник банка АКБ "ВПБ (ЗАО ДО г. Мытищи Московская обл.)"

\begin{abstract}
Аннотация
Статья посвящена рассмотрению аспектов развития образовательной среды. В ней рассмотрен организачионный механизм формирования образовательной среды в управлении образованием региона.

Ключевые слова: образовательная среда, управление знаниями, образование, университетский комплекс
\end{abstract}

\section{Summary}

The article is devoted to consideration of educational environment.

It regards the organizational mechanism of the mechanism of formation of educational environment in management of the education in regions.

Keywords: educational environment, knowledge management, education, university complex

\section{ВВЕДЕНИЕ}

В рамках современных тенденций развития экономики определенные отрасли развиваются на основе кластерной организации или самоорганизации. При этом, в процессе своего роста, используя современные информационные и организационные технологии, кластерная организация выходит за рамки классических территориальных форм объединения и формирует потребность в подготовке квалифицированных кадров на различной территории в пределах функционирования кластерного образования. Соответственно, возникает потребность в развитии определенной образовательной среды и даже формирования образовательного кластера на основе управления знаниями.

Этим вопросам посвящены труды Г.В. Атаманчук, В.А.Бабурина, В.Д. Граждан, А.И. Демидова, Г.Д. Дроздова, И.О. Котляровой, А.Г. Кузнецова, П.Н. Лебедева, Д.В. Обухова, Г.В. Осипова, А.Л.Пастухова, А.А. Савельева, В.А. Садовничего, С.И. Солонина, С.Б. Суровова, Ю.Г Татура, Феклистова И.Ф., В.Д. Шадрикова, Шамовой Т.И., Е.Р. Ярской-Смирновой и др.

Теоретические и методические аспекты применения управления знаниями (менеджмент знаний) в образовании представлены в научных, методических трудах и опубликованных результатах исследований Е.Ю. Игнатьевой, А.А. Кузьминой А.А., Т. Нодайна, А.Л. Пастухова, Л. Петридес, Д.Кидуэлл, К. Вандер Линд, С. Джонсон. 


\section{РЕЗУЛЬТАТЫ И ИХ ОБСУЖДЕНИЕ}

Чтобы понять основные принципы и тенденции формирования образовательной среды и образовательного кластера, рассмотрим формирование кластерной организации хозяйства в различных сферах сервиса.

Так, например, предприятия жилищно-коммунального хозяйства составляют основу непосредственной среды обитания современного человека, поскольку понятия «качество жилья» и «качество жизни» тесно связаны с качеством его эксплуатации. Роль данной сферы велика в развитии всех без исключения территориальных кластеров, но особенно она возрастает в случае, если речь идет об отраслях, предъявляющих повышенные требования к квалификации персонала. Руководство крупных фирм по мере разрастания своего бизнеса все меньше привязано к месту его исторического возникновения и может принять решение о переносе главного офиса, в котором сосредоточены ключевые сотрудники, в места с более благоприятной средой обитания, при условии достаточного развития в них транспорта и связи, а также рассредоточении определенных функциональных подразделений. Или, в случае использования технологий аутсорсинга, в рамках кластера коллективно использовать определенные подразделения или сооружения на разных территориях. Такая свобода может стать основой формирования мульти-территориального кластера, не имеющего других преимуществ для основной отрасли специализации перемещенного предприятия [1].

Развитие предприятий банковской сферы и финансового бизнеса исторически следуют за ростом предприятий основных отраслей, использующих преимущества территорий в качестве источника этого роста. Банки, вырастая из обслуживающих добывающий производственный или обрабатывающий сектор предприятий, сами начинают превращаться в источники конкурентоспособности территорий и привлекают предприятия отраслей, не входящих в основу кластера. Этот эффект проявляется в случае концентрации банками значительных финансовых ресурсов и превращения их в надежное звено финансовой инфраструктуры. Наличие последней является одним из основных показателей качества инвестиционного климата территории.

При этом банковский сектор активно использует систему коммуникации и может как входить в состав определенного кластерного образования, сформированного по отраслевому или технологическому принципу, так и формировать мультикластер в банковском секторе экономики. В этом случае, возникает необходимость интеграции образовательных программ учебных заведений обеспечивающих кадрами организации банковского сервиса. Учитывая, что кредитование субъектов экономических отношений производится в разных отраслях и территориях, что формирует инфраструктурные условия организации мультикластерных систем [2].

Ресторанный бизнес развивается повсеместно, где наблюдается концентрация людей вследствие развития территорий. Крупные города дают почву для развития отдельных предприятий ресторанной сферы в крупные сетевые структуры, способные выходить в другие 
регионы и превращаться в глобальные предприятия. Центральные подразделения таких предприятий способны увеличить конкурентоспособность территорий и мест их размещения, но перспективы превращения такой территории в «ресторанный кластер» сомнительны и не подтверждены практикой. Рестораны наряду с другими предприятиями сферы обслуживания выполняют функцию повышения комфортности среды обитания и уже упомянутого гигиенического фактора. Отсутствие или неразвитость предприятий данной сферы может послужить серьезным препятствием для формирования и развития территориальных кластеров на основе других отраслей. Как следствие - ослабление конкурентоспособности территории, даже при наличии других существенных преимуществ для основных отраслей.

Особую роль рестораны играют в обслуживании рекреационных территорий, являющихся источником дохода туристических предприятий. Туристическая отрасль является важнейшей частью экономики многих регионов. Туризм может использовать особенности территорий в качестве основы формирования территориального рекреационного кластера, существенными звеньями которого являются рестораны и гостиницы. С развитием Интернет, а вместе с ним и возможности самостоятельно, без помощи предприятий - турагентов, организовывать собственный отдых и поездки, рекреационное развитие территорий все меньше зависит от политики фирм - туроператоров и больше является следствием активности предприятий сферы обслуживания приезжающих. Руководство предприятий сервиса, используя современные методы управления и инструменты маркетинга, переходит от обслуживания «клиентов с улицы» к целенаправленной дифференциации своей работы. В результате данного процесса появляются настоящие «сервисные кластеры», в которых конкурентоспособность территории полностью базируется на активности предприятий сервиса и качестве обслуживания. Кроме того, разработка туристических маршрутов, объединяющих несколько территорий, позволяет формировать туристические мультикластерные образования, что предполагает необходимость подготовки специалистов в сфере туризма, что возможно с помощью применения дистанционных технологий $[3]$.

Инновационные кластеры также, как правило, выходят за пределы определенных территориальных систем. Культура инноваций продемонстрировала связь эффективности их развития с формированием научных комплексов и технопарков как отдельных территорий, где обеспечено высокое качество непосредственной среды обитания сотрудников, так и мультитерритоиальных университетских комплексов. В отдельных сферах инноваций, не связанных с дорогостоящим лабораторным оборудованием, инвестиции в образовательную сферу могут составлять основу создания научных комплексов.

Связь в настоящее время стала частью информационного бизнеса вследствие распространения цифровых технологий. Тем не менее, исходный смысл деятельности в отрасли обеспечение коммуникации между субъектами бизнеса как на территории кластера, таки по всему миру [4]. 
Информационный бизнес делает процесс установления полноценной связи независимым от наличия стационарных сетей связи на любой территории. Местным фактором остается обеспечение надежного энергоснабжения, к качеству которого компьютерное оборудование особенно чувствительно. Традиционно связь как отрасль развивалась в рамках государственного сектора, что обусловлено ее военным значением. С появлением ИТ-технологий и Интернет в отрасли развился и стал преобладающим коммерческий сектор. Появились территориальные кластеры на основе роста числа предприятий, разрабатывающих технологии и производящих оборудование для связи. Трансформация связи из отрасли, обслуживающей основную, в доминирующую в кластере возможна при наличии некой «критической массы квалификации», которая может сложиться исторически на данной территории, а может и быть искусственно создана в результате проведения мероприятий региональной политики и политики в области научно-технического прогресса [5].

Соответственно информационные технологии, не связанные с определенной территорией, в настоящее время являются важнейшим элементом современных образовательных систем и могут объединять несколько образовательных учреждений в определенный мультикластер, формируя образовательную среду.

Кроме того, вариантом мультикластера является инновационно-образовательная среда как эффективная форма развития университетского комплекса.

Формирование двух типов кластерных моделей с участием университетских комплексов преследует следующие цели:

1. Формирование кластера на основе университетского комплекса, включающего в себя различные образовательные учреждения, связанные системой непрерывного образования; научнообразовательные центры, бизнес-инкубаторы и малые инновационные предприятия, связанные с учреждениями высшего профессионального образования; профильные НИИ и производственные предприятия. В этом случае, университетский комплекс будет являться центром разработки и внедрения новых инновационных центров, подобных «Силиконовой долине» [6].

2. Вхождение университетского комплекса в уже существующий или формируемый кластер, объединяющий предприятия на территориальной, технологической, кооперативной или иной кластерной основе. В этом варианте, университетский комплекс может стать устойчивой основой подготовки кадров для предприятий всего кластера с учетом соответствия специальностей и специализаций программ высшего профессионального образования требованиям, предъявляемым руководством предприятий к компетенциям выпускников.

3. Возможно мультикластерное развитие университетского комплекса, связанное с подготовкой специалистов для нескольких кластеров. В этом случае будет рационально деление университетского комплекса и даже структуры входящих в него образовательных учреждений по кластерному принципу.

При этом следует отметить, что в зависимости от региона, его экономического и социального развития, плотности населения и развития инфраструктуры, а также концепции 
развития самих университетских комплексов возможна интеграция университетского комплекса одновременно в несколько образований на основе стратегий развития отдельных подразделений вуза или организаций, входящих в состав университетского комплекса [7].

Например, сетевой университет, создаваемый на базе ГОУ ВПО «СПбГУСЭ», имея в своем составе несколько институтов, входил одновременно на территории Санкт-Петербурга и Ленинградской области в такие кластера как автомобильный, туристический, логистический. Кроме того, не исключено, что отдельные вузы, входящие в Национальный научнообразовательный инновационно-технологический консорциум вузов сервиса, одновременно взаимодействовали с производственными, коммерческими, научными организациями, относящимися к развивающимся отраслям на территории расположения данного учебного заведения.

В контексте понимания кластера как формы социально-экономической активности, объединяющей различные организации на экономической, технологической, территориальной, корпоративной и иной основе, включающей также организации, обеспечивающие сервисное обслуживание, подготовку кадров, выполняющих НИР и ОКР, важную роль в реализации кластерной политики России может осуществить система университетских комплексов.

Во-первых, социоэкономической целью системы профессионального образования является повышение качества людских ресурсов, формирование компетенций, необходимых для высокопроизводительного труда. Взаимодействие малых инновационных предприятий и учебных заведений внутри кластера позволит учебным заведениям скорректировать учебные программы с максимальным учетом потребностей потенциального работодателя будущих выпускников.

Во-вторых, учащиеся могут в период прохождения производственных практик, в процессе участия в работе научно-образовательных центров и бизнес-инкубаторов при учреждениях высшего профессионального образования смогут выполнять исследовательскую практическую работу. В том числе учащиеся также смогут проводить исследования технологий, оборудования и ценовой политики в определенном секторе экономики, что позволит формировать базы данных для предприятий целого кластера и высвобождать высокопрофессиональных работников для выполнения иных видов работ. Это будет способствовать улучшению информированности работников маркетинговых подразделений организаций, входящих в кластер, и в конечном итоге влиять на улучшение продвижения продукции на отечественном и даже мировом рынке.

В-третьих, учащиеся смогут проводить мониторинг внутренней среды всего кластера и совместно с профессорско-преподавательским составом вуза разрабатывать рекомендации по улучшению внутрикорпоративного взаимодействия с целью достижения экономического и организационного синергийного эффекта на уровне всего кластера [8].

В этом контексте возможно формирование двух типов кластерных моделей с участием университетских комплексов. 


\section{ВЫВОДЫ}

Таким образом, применяя кластерный подход, можно не только использовать новые для России инновационные тенденции в развитии университетского комплекса и приблизить образовательный процесс к потребностям отечественной экономики, но и создать эффективную систему межорганизационного и даже межотраслевого взаимодействия для максимально быстрого достижения реальных экономических результатов от подготовки квалифицированных кадров в системе непрерывного профессионального образования в рамках университетского комплекса.

Использование образовательных технологий и методов управления знаниями возможно для создания и развития эффективной образовательной среды, объединяющей не только образовательные учреждения, но являющейся важным институциональным ядром взаимодействия образования, бизнеса и государства.

\section{ЛИТЕРАТУРА}

1. Векшинский, А.А. Поиск инновационной модели формирования стратегии развития вуза на основе принципов модернизационного маркетинга / А.А.Векшинский, В.А.Бабурин // Журнал Технико-технологические проблемы сервиса № 14.-Т.4. Из-во: СПбГУСЭ, 2007, С. 88-98. - С.94.

2. Векшинский, А.А. Поиск инновационной модели формирования стратегии развития вуза на основе принципов модернизационного маркетинга / А.А.Векшинский, В.А.Бабурин // Журнал Технико-технологические проблемы сервиса № 14.-Т.4. Из-во: СПбГУСЭ, 2007, С. 88-98. - С.89.

3. Пастухов, А.Л. Интеграция бизнеса и образования в процессе инновационного развития подготовки кадров: коллективная монография / Бабурин В.А., Векшинский А.А. и др. - СПб.: Издво СПбГУСЭ, 2009 - 293 с. - С. 45.

4. Бабурин, В.А. Инновационно-образовательные комплексы в системе высшей школы: коллективная монография / Бабурин В.А., Векшинский А.А. и др. - СПб.: Изд-во СПбГУСЭ, 2007 -283 c. - C. 110.

5. Бабурин, В.А. Инновационно-образовательные комплексы в системе высшей школы: коллективная монография / Бабурин В.А., Векшинский А.А. и др. - СПб.: Изд-во СПбГУСЭ, 2007 -283 c. - C. 115 .

6. Пастухов, А.Л. Инновации в образовании как фактор развития региона / А.Л. Пастухов // Университетский комплекс - форма инновационного развития образовательных учреждений: материалы ІІІ Всероссийской научно-практической конференции. - СПб, 2009 - С. 169-171.

7. Пастухов, А.Л. Инновации в образовании как фактор развития региона / А.Л. Пастухов // Университетский комплекс - форма инновационного развития образовательных учреждений: материалы III Всероссийской научно-практической конференции. - СПб, 2009 - С. 169-171.

8. Пастухов, А.Л. Модель формирования университетского комплекса на основе кластерного подхода/ А.Л. Пастухов // Экономика и управление - 2010 - № 8 (58) - С.96-101. 